\title{
FORMULASI DAN UJI SIFAT FISIK PASTA GIGI GEL DARI EKSTRAK KERING JAHE MERAH (Zingiber Officinale Roscoe Var. Rubrum)
}

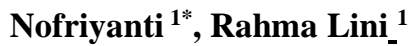 \\ ${ }^{1}$ Sekolah Tinggi Ilmu Farmasi Riau : Jalan Kamboja, Simpang Baru Panam, Pekanbaru, 28928 \\ e-mail :nofriyati@stifar-riau.ac.id
}

\begin{abstract}
ABSTRAK
Rimpang jahe merah memiliki komponen volatile (minyak atsiri) dan non volatile (oleoresin) yang telah umum digunakan sebagai antibakteri. Pada penelitian akan diformulasi dan diuji sifat fisik gel pasta gigi dari ekstrak kering jahe merah (zingiber officinale roscoe var rubrum). Penelitian ini bertujuan untuk memformulasikan dan menguji sifat fisik sediaan pasta gigi gel yang baik dari ekstrak kering jahe merah dengan konsentrasi 3\% dan 4\%. Formulasi dilakukan evaluasi fisik berupa uji organoleptis, uji pH, uji homogenitas, uji daya sebar, uji daya berbusa dan uji penerimaan. Hasil evaluasi fisik didapatkan konsentrasi $3 \%$ memiliki penilaian yang baik karena diperoleh hasil yang stabil selama empat minggu penyimpanan, sedangkan untuk konsentrasi $4 \%$ mengalami pemisahan pada minggu kedua penyimpanan di mana sediaan menjadi dua fase yaitu minyak dan basis. Hal ini menandakan ekstrak kering jahe merah dengan konsentrasi $3 \%$ dapat diformulasi dan memiliki stabilitas fisik pasta gigi gel yang baik selama 4 minggu penyimpanan.
\end{abstract}

Kata Kunci : Ekstrak Jahe Merah, Formulasi, Pasta Gigi, Stabilitas Sediaan

\begin{abstract}
Red Ginger has a volatile and non volatile components who has known to used as an antibacterial. This research will be formulated and physical properties tested of dry extract from red ginger (zingiber officinale roscoe var rubrum) in gel toothpaste has been conducted. This study aims to formulate and test the physical properties of a good gel toothpaste preparation from dry red ginger extract with concentration $3 \%$ and $4 \%$. Formulation is subjected to physical evaluation in the form of organoleptic test, $\mathrm{pH}$ test, homogeneity test, dispersion test, foaming test and acceptance test. The result of physical properties test is showed that concentrasion 3\% has a good assessment because it is obtained stable for four weeks at storage, whereas concentration $4 \%$ in the second week of storage undergoes separation into two phases, namely oil and base. This indicates that the dry extract of red ginger at concentration of $3 \%$ can be formulated and has good physical stability for the gel toothpaste for 4 weeks of storage.
\end{abstract}

Keywords: Red Ginger Extract, Formulation, Toothpaste, Preparation Stability

\section{PENDAHULUAN}

Sejak zaman dahulu masyarakat Indonesia mengenal dan memakai tanaman berkhasiat obat menjadi salah satu upaya dalam penanggulangan masalah kesehatan yang dihadapi. Salah satu tumbuhan berkhasiat obat diantaranya adalah rimpang dari tumbuhan jahe merah (Zingiber officinale roscoe var. Rubrum). Rimpang jahe merah sudah digunakan sebagai obat secara turun temurun karena mempunyai komponen volatile (minyak atsiri) dan non volatile (oleoresin) paling tinggi.

Jahe merah mempunyai kandungan kimia yaitu flavonoid, fenol, minyak atsiri, dan tanin (Fissy, 2013). Senyawa turunan fenol adalah gingerol, shogaol, dan resin merupakan penyusun utama dari oleoresin jahe merah. Kandungan oleoresin inilah yang menyebabkan rasa pedas pada jahe merah.

Minyak atsiri merupakan senyawa yang menyebabkan jahe memiliki aroma khas yang harum. Kandungan kimia minyak atsiri terdiri dari zat zingiberen dan zingiberol yang mempunyai daya bunuh terhadap mikroorganisme (Tilong, 2013).
Rimpang jahe merah biasa digunakan sebagai obat masuk angin, gangguan pencernaan, sebagai analgesik, antipiretik, anti inflamasi, antibakteri, menurunkan kadar kolesterol, mencegah depresi, impotensi, dan lain-lain (Hapsoh \& Julian, 2008).

Dari hasil penelitian yang dilakukan oleh (Kusumowati $d k k$, , 2012) menyatakan ekstrak kering jahe merah dapat menghambat bakteri Staphylococcus aureus, Escherichia coli dan Candida albicans. Menurut penelitian yang dilakukan oleh (Azkiya $d k k$., 2017) tentang evaluasi sifat fisik krim ekstrak kering jahe merah (Zingiber officinale Roscoe. var. rubrum) sebagai anti nyeri telah memenuhi sifat krim yang baik.

Pasta gigi merupakan suatu sediaan semi padat untuk memoles dan membersihkan permukaan gigi yang terdiri dari bahan pengikat, pembersih, surfaktan, humektan, dan bahan tambahan lain yang bertujuan agar zat aktif dapat bekerja pada permukaan gigi untuk melindungi dari kerusakan yang disebabkan oleh bakteri mulut seperti streptococcus muntans tanpa merusak gigi atau membran mukosa mulut (Elmitra, 2017). 
Pada penelitian ini sediaan yang dibuat adalah pasta gigi gel dari ekstrak kering jahe merah. Pemilihan bentuk sediaan pasta gigi gel karena memiliki beberapa keuntungan, yaitu tidak lengket dan viskositas gel yang tidak mengalami perubahan yang berarti pada saat pengimpanan (Liebermann et al, 1996).

Penelitian ini bertujuan untuk memformulasi dan menguji sifat fisik dari sediaan pasta gigi gel yang baik yang mengandung ekstrak kering jahe merah. Berdasarkan uraian diatas, maka peneliti tertarik untuk memformulasi sediaan pasta gigi gel dari ekstrak kering jahe merah (Zingiber officinale roscoe Var. Rubrum).

\section{METODOLOGI PENELITIAN \\ Alat dan Bahan}

Alat-alat yang digunakan dalam penelitian ini adalah neraca analitik, alat-alat formulasi dan evaluasi serta $\mathrm{pH}$ meter.

Bahan-bahan yang digunakan dalam penelitian ini adalah ekstrak kering jahe merah (CV Eteris Nusantara), $\mathrm{CaCO}_{3}, \mathrm{Na} . \mathrm{CMC}$, gliserin, Na. Lauryl Sulfat, Sorbitol, Na. Benzoat dan Aquadest (PT. Brataco, Indonesia)

\section{Prosedur Kerja}

a. Pemeriksaan Zat aktif

1. Organoleptis (Depkes RI, 2008)

Pemeriksaan meliputi bentuk, bau, dan warna.

2. Susut pengeringan (Depkes RI, 2008)

Timbang seksama $1 \mathrm{~g}$ dalam botol yang sebelumnya telah dipanaskan pada suhu penetapan dan ditara, ratakan dengan menggoyangkan botol hingga membentuk lapisan setebal 5-10 mm, masukkan ke oven, buka tutup botol keringkan pada suhu penetapan hingga bobot tetap.

Perhitungan :

$$
=\frac{\begin{array}{c}
\text { susut pengeringan } \\
\text { berat sebelum pemanasan }- \text { berat akhir }
\end{array}}{\text { berat sebelum pemanasan }} \times 100 \%
$$

3. Kelarutan (Elmitra, 2017)

Ekstrak kering jahe merah ditimbang sebanyak $1 \mathrm{~g}$, kemudian ditambahkan masing-masing pelarut yang digunakan untuk uji kelarutan sampai ekstrak larut. Catat volume pelarut yang terpakai.

\section{b. Formulasi Pasta Gigi Gel Ekstrak Kering Jahe Merah (Poucher, 2000)}

Tabel 1. Formulasi Pasta Gigi Gel Ekstrak Kering Jahe Merah

\begin{tabular}{|c|c|c|c|}
\hline Bahan & F1 (\%) & F2 (\%) & Fungsi \\
\hline $\begin{array}{c}\text { Ekstrak kering jahe } \\
\text { Merah }\end{array}$ & 3 & 4 & Bahan Aktif \\
\hline Na.CMC & 1,5 & 1,5 & Gelling agent \\
\hline CaCO3 & 20 & 20 & Bahan abrasive \\
\hline Gliserin & 20 & 20 & Humektan \\
\hline Sorbitol & 20 & 20 & Humektan \\
\hline Na. Lauryl Sulfat & 1 & 1 & Surfaktan \\
\hline Na. Benzoate & 0,1 & 0,1 & Pengawet \\
\hline Aquadest ad & 100 & 100 & Pelarut \\
\hline
\end{tabular}

\section{c. Pembuatan Pasta Gigi Gel Ekstrak Kering Jahe Merah}

Mortir dan stamfer dipanaskan dalam air panas, setelah panas air dkeluarkan dan dikeringkan. $\mathrm{Na} \mathrm{CMC}$ ditaburkan di atas air panas dalam mortir (sebanyak 20xbobot Na.CMC/15ml) diamkan sampai mengembang selama \pm 15 menit, kemudian gerus sampai terbentuk basis gel yang baik (M1). Setelah itu $\mathrm{Na}$. lauryl sulfat dan $\mathrm{Na}$. benzoate dilarutkan dengan air sisa, aduk sampai homogen (M2). $\mathrm{CaCO} 3$ digerus dan ditambahkan Glyserol serta sorbitol, kemudian digerus homogen, (M1) ditambahkan lalu digerus sampai terbentuk masa gel yang baik, (M2) ditambahkan sedikit demi sedikit dan digerus hingga terbentuk masa pasta gigi gel yang baik. Ekstrak kering jahe merah dimasukkan terakhir ke dalam masa pasta gigi gel dan digerus homogen. Sediaan dimasukkan dan disimpan dalam wadah kemudian dilakukan evaluasi sifat fisik sediaan pada suhu kamar setiap minggu selama 4 minggu penyimpanan.

\section{d. Evaluasi Pasta Gigi Gel Ekstrak Kering Jahe Merah}

\section{Pemeriksaan organoleptis (Anonim, 1995)}

Meliputi pemeriksaan terhadap bentuk, warna serta bau yang dilakukan secara visual.

\section{Pemeriksaan pH (Martin et al, 1993)}

Pemeriksaan $\mathrm{pH}$ dilakukan dengan alat $\mathrm{pH}$ meter. Pengukuran dilakukan dengan cara 1 gram sediaan diencerkan dengan air suling hingga $10 \mathrm{ml}$. Elektroda dicelupkan dalam wadah tersebut. Persyaratan $\mathrm{pH}$ sediaan pasta gigi yaitu 4,5 -10,5 (Anonim, 1995)

3. Pemeriksaan Homogenitas (Carter, 1975) Pemeriksaan homogenitas dilakukan dengan 
cara sebagai berikut, 1 gram sediaan diletakkan pada sekeping kaca yang transparan, kemudian dilihat secara organoleptis dimana sediaan harus menunjukkan susunan yang homogen dan tidak boleh terlihat adanya bintik-bintik partikel.

4. Uji daya menyebar (Voigt, 1994)

Sediaan sebanyak 0,5 gram diletakkan dengan hati-hati di atas plastik transparan yang dialasi kertas grafik, dibiarkan sesaat (15 detik) dan dihitung luas daerah yang diberikan oleh sediaan, lalu ditutup dengan plastik transparan. Kemudian diberi beban tertentu di atasnya $(1 \mathrm{~g}, 3 \mathrm{~g}, 5 \mathrm{~g}, 10 \mathrm{~g}$ dan $20 \mathrm{~g}$ ) dan dibiarkan selama 60 detik. Lalu di hitung pertambahan luas yang diberikan oleh sediaan.

5. Uji Daya Busa

Sebanyak 0,5 gram sediaan pasta gigi dengan ditambahkan air suling lalu dimasukkan ke dalam gelas ukur 100ml. Kocok selama 20 detik dengan cara membolak balikkan gelas ukur secara beraturan diamkan selama 5 menit. Ukur tinggi busa menggunakan mistar (kumar et al, 2009).

\section{Uji Penerimaan}

Uji penerimaan merupakan salah satu uji penerima dimana dalam uji ini panelis diminta untuk menilai kesukaannya terhadap sediaan pasta gigi gel yang meliputi kesukaan bau, konsistensi dan warna yang dibuat rentang nilai kesukaan atau ketidak sukaan. Panelis diminta dalam uji kesukaan ini sebanyak 10 orang (Wagiono, 2003) (Wasitaatmadja, 1997).

Uji ini dilakukan dengan menggunakan skala 0 sampai 5yaitu :

$1=$ sangat tidak suka

2 = agak tidak suka

3 = agak suka

$4=$ suka

5 = sangat suka

\section{HASIL DAN PEMBAHASAN}

Penelitian ini bertujuan untuk memformulasi dan menguji sifat fisik sediaan pasta gigi gel dari Ekstrak kering Jahe Merah (Zingiber Officinale Roscoe Var. Rubrum), apakah ekstrak kering jahe merah tersebut dapat menghasilkan bentuk sediaan pasta gigi gel yang baik.

Sebelum dilakukan formulasi, ekstrak kering jahe merah diperiksa dahulu organoleptisnya susut pengeringannya dan kelarutannya yang disesuaikan dengan sertifat analisisnya.
Tabel 2. Hasil Pemeriksaan Ekstrak Kering Jahe Merah

\begin{tabular}{|c|c|c|c|c|}
\hline No & Pemeriksaan & $\begin{array}{c}\text { Persyaratan } \\
\text { (Sertifikat Analis) }\end{array}$ & $\begin{array}{c}\text { Farmakope } \\
\text { Herbal Indonesia }\end{array}$ & Pengamatan \\
\hline \multicolumn{5}{|c|}{ Organoleptis } \\
\hline \multirow[t]{4}{*}{1} & Warna & $\begin{array}{c}\text { Coklat } \\
\text { kekuningan }\end{array}$ & $\begin{array}{c}\text { Coklat } \\
\text { Kekuningan }\end{array}$ & $\begin{array}{c}\text { Coklat } \\
\text { kekuningan }\end{array}$ \\
\hline & Bau & Khas & Khas & Khas \\
\hline & Bentuk & Bubuk & Kental & Bubuk \\
\hline & \multicolumn{4}{|c|}{ Kelarutan } \\
\hline \multirow[t]{2}{*}{2} & Etanol & - & - & $6,5 \mathrm{ml}$ \\
\hline & Air & - & - & $7,6 \mathrm{ml}$ \\
\hline 3 & $\begin{array}{c}\text { Susut } \\
\text { Pengeringan }\end{array}$ & $<5 \%$ & $<10$ & $2 \%$ \\
\hline
\end{tabular}

Perhitungan :

$$
\begin{aligned}
& \text { susut pengeringan } \\
& =\frac{\text { berat sebelum pemanasan }- \text { berat akhir }}{\text { berat sebelum pemanasan }} \times 100 \% \\
& =\frac{46,68-46,46}{48,46} \times 100 \% \\
& =2 \%
\end{aligned}
$$

Hasil uji organoleptis sediaan pasta gigi gel pada F1 selama 4 minggu penyimpanan menunjukkan tidak terjadi perubahan terhadap konsistensi, bau dan warna, sedangkan pada F2 mengalami perubahan setelah 2 minggu penyimpanan, di mana sediaan memisah menjadi 2 fase yaitu fase basis dan fase minyak hal ini menunjukan bahwa F2 tidak stabil. Pemisahan ini terjadi karena ekstrak kering jahe merah tidak dalam keadaan terlarut, melainkan terdispersi dalam gel. Hal ini disebabkan karena adanya faktor-faktor yang menganggu kualitas seperti konsentrasi zat aktif, cahaya, kelembaban/ kandungan air dan suhu (Agoes, 2009). Selain itu, penggunaan wadah pada penelitian ini berupa pot plastik juga diduga ikut mempengaruhi kualitas dari pasta gigi dan komponen utama yang terkandung pada jahe merah bersifat mudah menguap (Depkes RI, 1978).

Tabel 3. Hasil Uji Organoleptis Pasta Gigi Gel Ekstrak Kering Jahe Merah

\begin{tabular}{cccccc}
\hline \multirow{2}{*}{ Formula Pemeriksaan } & \multicolumn{4}{c}{ Minggu ke- } \\
\cline { 2 - 6 } F1 $(3 \%))$ & B & II & III & IV \\
\cline { 2 - 6 } & Bentuk & Kental & Kental & Kental & Kental \\
\cline { 2 - 6 } & Warna & Krem & Krem & Krem & Krem \\
\hline \multirow{3}{*}{ F2 $(4 \%)$} & Bentuk & Kental & $\begin{array}{c}\text { Agak } \\
\text { cair }\end{array}$ & Agak cair & Cair \\
\cline { 2 - 6 } & Bau & Khas & Khas & Khas & Khas \\
\cline { 2 - 6 } & Warna & Krem & Krem & Krem & Krem \\
\hline
\end{tabular}




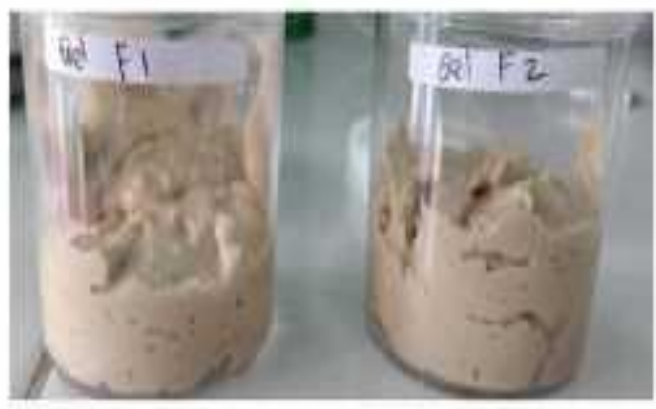

Gambar 1. Sediaan Pasta Gigi Gel Ekstrak Kering Jahe Merah Pada Minggu ke-1

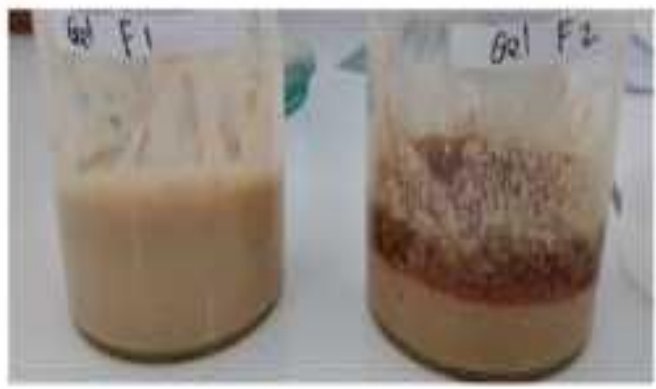

Gambar 2. Sediaan Pasta Gigi Gel Ekstrak Kering Jahe Merah Pada Minggu ke-II

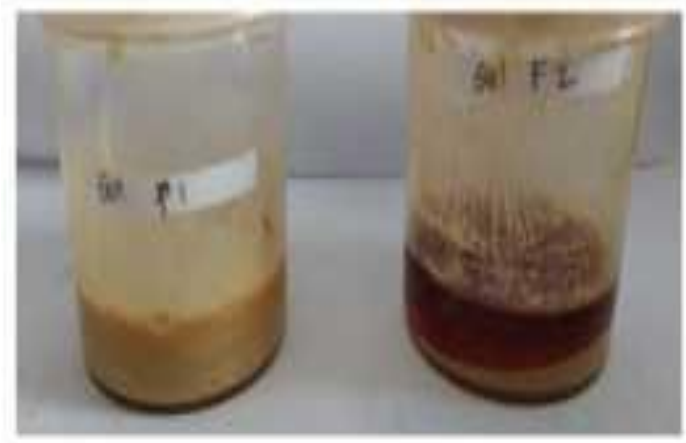

Gambar 3. Sediaan Pasta Gigi Gel Ekstrak Kering Jahe Merah Pada Minggu ke-III

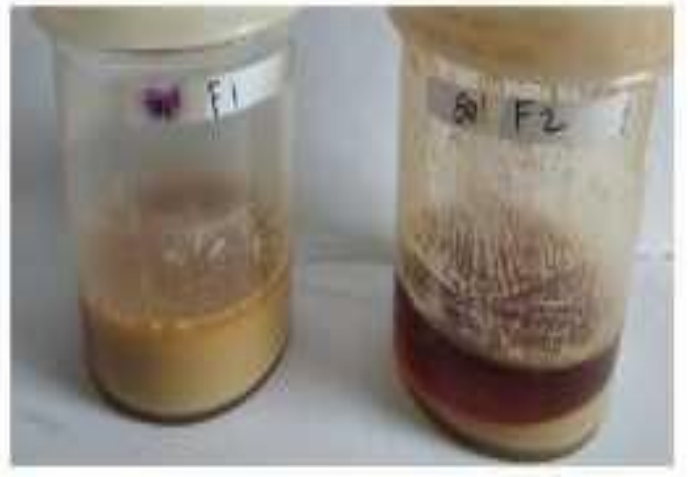

Gambar 4. Sediaan Pasta Gigi Gel Ekstrak Kering Jahe Merah Pada Minggu ke-IV
Suhu memiliki pengaruh terhadap hasil pengukuran $\mathrm{pH}$ (Barron dkk, 2006). Standar pengukuran $\mathrm{pH}$ pasta gigi menurut SNI (Standar Nasional Indonesia) adalah pada suhu $25^{\circ} \mathrm{C}$. Syarat mutu $\mathrm{pH}$ sediaan pasta gigi gel yaitu 4,5-10,5 supaya tidak mengiritasi mukosa mulut (Anonim, 1995). pH sediaan yang dibuat memenuhi persyatan yang telah ditetapkan yaitu F1 8,34-8,81, sedangkan pH F2 yang diamati selama 2 minggu penyimpanan yaitu $8,49-8,59$.

Tabel 4. Hasil Uji pH Pasta gigi gel Ekstrak Kering Jahe Merah

\begin{tabular}{ccccc}
\hline \multirow{2}{*}{ Formula } & \multicolumn{4}{c}{ Minggu ke- } \\
\cline { 2 - 5 } & I & II & III & IV \\
\hline F1 (3\%) & 8,34 & 8,73 & 8,91 & 8,81 \\
\hline F2 (4\%) & 8,49 & 8,59 & 8,72 & 8,64 \\
\hline
\end{tabular}

Homogenitas adalah salah satu faktor penting dan merupakan tolak ukur kualitas sediaan pasta gigi karena bahan-bahan yang digunakan harus terdistribusi merata dalam sediaan pasta gigi sehingga bahan-bahan tersebut terdispersi dan tercampur secara homogen pada medium dispersi (basis) agar dapat memberikan efeknya secara maksimal. Sediaan gel dikatakan homogen bila terdapat persamaan warna yang merata dan tidak adanya partikel atau bahan kasar yang dapat diraba. Persyaratan homogenitas gel dimaksudkan agar bahan aktif dalam gel terdistribusi merata. Selain itu agar pasta gigi gel tidak mengalami pemisahan antara padatan dan air. Ketidakhomogenan yang dimaksud adalah gradasi warna pada gel (Setyaningrum, 2013). Berdasarkan pemeriksaan diperoleh hasil bahwa pada F1 menghasilkan sediaan yang homogen selama 4 minggu penyimpanan dan F2 homogen pada minggu pertama dan kedua penyimpanan, namun pada minggu kedua penyimpanan sediaan tidak homogen lagi karena membentuk dua fase yaitu minyak dan basis.

Tabel 5. Hasil Uji Homogenitas Pasta gigi gel Ekstrak Kering Jahe Merah

\begin{tabular}{lllll}
\hline \multirow{2}{*}{ Formula } & \multicolumn{5}{c}{ Minggu ke- } \\
\cline { 2 - 5 } & I & II & III & IV \\
\hline F1 (3\%) & H & H & H & H \\
\hline F2 (4\%) & H & TH & TH & TH \\
\hline
\end{tabular}


Hasil uji daya sebar sediaan selama 4 minggu penyimpanan diperoleh sediaan pasta gigi gel F1 memiliki rentang daya sebar $1,6-4,1 \mathrm{~cm}$ dan sediaan pasta gigi gel F2 selama 2 minggu penyimpanan memiliki rentang daya sebar $1,5-5,5 \mathrm{~cm}$. Pasta gigi gel diharapkan mampu menyebar dengan mudah pada saat penggunaan. Pada pengamatan diperoleh semakin besar beban yang diberikan semakin besar pula daya menyebarnya.

Uji daya sebar sediaan gel dimaksudkan untuk mengetahui kemampuan menyebar gel saat dioleskan pada tempat target. Daya sebar gel yang baik yaitu antara 5-7 cm. Kemampuan menyebar adalah karakteristik penting dalam formulasi karena mempengaruhi transfer bahan aktif pada daerah target dalam dosis yang tepat, kemudahan penggunaan, tekanan yang diperlukan agar dapat keluar dari kemasan, dan penerimaan oleh konsumen (Garg dkk, 2002). Kedua formulasi yang dibuat masih belum memberikan hasil yang sesuai untuk diameter sebarnya. Hal ini disebabkan karena konsentrasi $\mathrm{Na}$. CMC yang digunakan terlalu kecil sehingga sediaan menjadi kurang elastis.

Tabel 6. Hasil Pemeriksaan Daya Sebar Pasta gigi gel Ekstrak kering jahe Merah(Zingiber Officinale Roscoe Var. Rubrum).

\begin{tabular}{ccccccc}
\hline \multirow{2}{*}{ Formula } & Beban & \multicolumn{6}{c}{ Diameter (cm) Minggu ke- } & Syarat \\
& & \multicolumn{5}{c}{ (5-7 cm) } \\
\cline { 2 - 7 } & & 1 & 2 & 3 & 4 & \\
\hline & $1 \mathrm{~g}$ & 1.65 & 1.75 & 1.9 & 2.6 & \\
\cline { 2 - 7 } F1 (3\%) & $3 \mathrm{~g}$ & 2.1 & 1.9 & 2.3 & 2.95 & \\
\cline { 2 - 7 } & $5 \mathrm{~g}$ & 2.05 & 1.95 & 2.5 & 3.25 & \\
\cline { 2 - 7 } & $10 \mathrm{~g}$ & 2.15 & 2.1 & 2.85 & 3.45 & \\
\cline { 2 - 7 } & $20 \mathrm{~g}$ & 2.6 & 2.35 & 3.35 & 4 & Tidak Sesuai \\
\cline { 2 - 7 } & $1 \mathrm{~g}$ & 1.6 & 2.1 & 3.05 & 3.2 & \\
\cline { 2 - 7 } & $3 \mathrm{~g}$ & 1.65 & 2.95 & 3.35 & 4.1 & \\
\cline { 2 - 7 } & $5 \mathrm{~g}$ & 2.1 & 3.1 & 3.8 & 4.4 & \\
\cline { 2 - 7 } & $10 \mathrm{~g}$ & 2.25 & 3.25 & 4.15 & 4.8 & \\
\cline { 2 - 7 } & $20 \mathrm{~g}$ & 2.45 & 3.4 & 4.6 & 5.25 & $\begin{array}{c}\text { Sesuai } \\
\text { (Sediaan } \\
\text { memisah) }\end{array}$ \\
\hline
\end{tabular}

Berdasarkan hasil pengukuran, tinggi busa semua formula mengalami perubahan ketinggian Terjadinya perubahan parameter tinggi busa karena parameter tinggi busa sangat tergantung pada surfaktan yang digunakan, kesadahan air, suhu ruangan saat pengukuran dan waktu pendiaman (Depkes RI, 1985). Ukuran tinggi busa yang dihasilkan dapat dikaitkan dengan nilai estetika yang disukai konsumen, karna konsumen cenderung lebih suka terhadap sediaan pasta gigi yang memiliki banyak busa.

Tabel 7. Hasil Pemeriksaan Daya Busa Pasta gigi gel Ekstrak kering jahe Merah (Zingiber Officinale Roscoe Var. Rubrum.

\begin{tabular}{lcccl}
\hline \multirow{2}{*}{ Formula } & \multicolumn{4}{c}{ Minggu ke- (cm) } \\
\cline { 2 - 5 } & I & II & III & IV \\
\hline F1 (3\%) & 2,2 & 3,2 & 2,7 & 2,0 \\
\hline F2 (4\%) & 2,0 & 4,5 & 3,0 & 2,5 \\
\hline
\end{tabular}

Dari hasil uji penerimaan sediaan F1 dan F2 yang diperoleh menunjukan bahwa dari segi warna, bau dan konsistensi, formulasi sediaan F1 memiliki penilaian lebih baik. Hal ini dikarenakan konsentrasi ekstrak yang digunakan dalam formulasi sediaan mempengaruhi warna, bau dan konsistensi yang lebih disukai para panelis. Sediaan dengan konsentrasi ekstrak yang lebih sedikit memiliki warna yang lebih baik, konsistensi yang lebih lembut dan aroma yang wangi yang tidak terlalu kuat. Sedangkan pada sediaan yang memiliki konstentrasi ekstrak lebih banyak menunjukan warna yang lebih gelap, konsistensi yang kurang baik ditandai dengan terjadinya pemisahan fasa dan aroma yang terlalu kuat dari ekstrak kering jahe merahnya.

Tabel 8. Hasil Uji Kesukaan F1Pasta gigi gel Ekstrak kering jahe Merah (Zingiber Officinale Roscoe Var. Rubrum).

\begin{tabular}{llll}
\hline Kategori & Warna & Bau & Konsistensi \\
\hline 1 & - & - & - \\
\hline 2 & - & - & - \\
\hline 3 & $50 \%$ & $30 \%$ & $10 \%$ \\
\hline 4 & $50 \%$ & $50 \%$ & $60 \%$ \\
\hline 5 & - & $20 \%$ & $30 \%$ \\
\hline
\end{tabular}

Keterangan :

5 = sangat suka

2 = agak tidak suka

$4=$ suka

1 = sangat tidak suka

3 = agak suka 
Jurnal Penelitian Farmasi Indonesia 10(1), Juni 2021

\section{KESIMPULAN}

Ekstrak kering jahe merah pada FI dengan konsentrasi 3\% memiliki stabilitas fisik yang lebih baik selama 4 minggu penyimpanan walaupun daya sebarnya masih belum sesuai, dibandingkan dengan ekstrak kering jahe merah pada FI dengan konsentrasi 4\%. Di mana karena pada minggu penyimpanan formula telah memisah menjadi dua fase yaitu minyak dan basis.

\section{DAFTAR PUSTAKA}

Agoes, G. 2012. Sediaan Farmasi Likuida-Semisolida. Bandung: ITB.

Anonim. 1995. Syarat Mutu Pasta Gigi, SNI 12-3524-1995. BSN (Badan Standarisasi Nasional Indonesia). Jakarta.

Anonim. 2000. Parameter Standar Umum Ekstrak Tumbuhan Obat. Edisi 1, Direktorat Jenderal Pengawasan Obat dan Makanan, Direktorat Jenderal Pengawasan Obat Tradisional, Departemen Kesehatan Republik Indonesia, Jakarta.

Azkiya, Z., Ariyani, H. \& Nugraha, T.S. 2017. Evaluasi Sifat Fisik Krim Ekstrak Jahe Merah (Zingiber officinale Rosc. var rubrum) sebagai Anti Nyeri. Jurnal Current Pharmaceutica Sciences, 1: 12-18.

Baroon, J. J., C. Ashton, L. Geary. 2006.The Effect of Temperature on $p H$ Measurement. Technical Papers.Technical Services Department, Reagecon Diagnostic Ltd., Shanron Free Zone, Clare, Ireland.

Carter, S. 1975. Dispending for Pharmaceutical Student. $12^{\text {th }}$ Edition, Pitnam Medical, London.

Depkes RI. 1985. Materia Medika Indonesia. Jilid V, p. 55-58

Depkes RI 1995. Farmakope Indonesia edisi IV. Departemen Kesehatan Republik Indonesia. Jakarta

Elmitra .2017. Dasar - Dasar Farmasetika dan Sediaan Semi Solid. Yogyakarta: Penerbit CV Budi Utama.

Fissy S. O. 2013. Uji Efektifitas Sedian Gel anti Nyamuk Ekstrak Etanol Rimpang Jahe Merah (Zingiber Officinale Roscoe Var. Rubrum) Terhadap Propionibacterium Acnes Dan Straphylococcus
Epidermidis. Skripsi: Universitas Tanjungpura

Garg, A., Aggarwal, D., Garg, S., Sigla, A. K. (2002). Spreading of Semisolid Formulation: An Update. Pharmaceutical Technology. September 2002: 84102.

Hapsoh, H.Y., Julianti, E. 2008. Budidaya dan Teknologi Pascapanen Jahe, USUPress Art Design, Publishing \& Printing.

Kumar, K. Jaachandra, E. Grindhar, B.R. 2009. Formulation and Evaluation $O f$ Povidone Iodine Liquid Antidandruff Shampoo. Journal Of Pharmaceutical Science and Research. 1(3) : 108-111.

Kusumowati, I.T.D., Arifin, Z. \& Melannisa, R. 2012. Aktifitas Antimikroba Ektrak Etanol Jahe Merah (Zingiber officinale Roscoe var rubrum) Terhadap Strphylococcus aureus, Escherichia coli Dan Candida albicans. Skripsi, 66: 37-39.

Liebermann, H.A., Rieger, M.M., Banker, G.S. 1996. Pharmaceutical Dosage Forms: Disperse System $2^{\text {nd }}$ edition. Marcel Dekker, Inc. New York

Martin, A., Swarbrick, J.,Cammarata, A. 1993. Farmasi Fisik. Edisi III. Universitas Indonesia Press, Jakarta.

Nurhidayat Oki, Eram Tunggul P, Bambang Wahyono. 2012. Perbandingan Media Power Point Dengan Flip Chart Dalam Meningkatkan Pengetahuan Kesehatan Gigi dan Mulut. Unnes Journal of Public Health 1 (1) (2012).

Poucher, J., 2000, Poucher's Perfume Cosmetics and Soap, $10^{\text {th }}$ Ed., Netherlands: Kluwer Academic.

Setyaningrum, N.L. (2013). Pengaruh Variasi Kadar Basis HPMC dalam Sediaan Gel Ekstrak Etanolik Bunga Kembang Sepatu (Hibiscus rosa sinensis L.) terhadap Sifat Fisik dan Daya Antibakteri Pada Staphylococcus aureus. Naskah Publikasi.Universitas Muhammadiyah Surakarta.

Tilong, A. 2013. Kitab Herbal Khusus Terapi Stoke. Cetatakan ed. Jogyakarta: DMedika.

Voigt, R. 1994. Buku Ajar Teknologi Farmasi, Ed V, diterjemahkan oleh Soendani Noerno Soewandi, Gadjah Mada Univesity Press. Yogyakarta.

Wagiono, 2003. Menguji Kesukaan Secara Organoleptik. Bagian Proyek Pengembangan Kurikulum Direktorat Jendral Pendidikan dasar dan Menengah Departemen Pendidikan Nasional. Jakarta.

Wasitaatmadja, S.M. 1997. Penuntun Ilmu Kosmetik Medik. Jakarta : Penerbit Universitas Indonesia (UI-Press). 